\title{
A DFT Study on the Stepwise Fluorinated Methylenecyclopropane $\rightleftharpoons$ 1-Methylcyclopropene System
}

\author{
Salim M. Khalil \\ Chemistry Department, School of Basic Science, Academy of Graduate Studies, \\ P. O. Box 79031, Tripoli, Libya \\ Reprint requests to S.M. K.; E-mail: salimkhali12002@yahoo.com
}

Z. Naturforsch. 63a, $42-48$ (2008); received July 5, 2007

\begin{abstract}
Density functional theory (DFT) calculations have been performed to calculate the optimized geometries of stepwise fluorinated methylenecyclopropanes and 1-methylcyclopropenes. Increasing the number of fluorine atoms caused a destabilization of methylenecycopropane. Perfluorinated 1-methylcyclopropene was found to be present in substantial concentration. This is supported by calculations of the Gibbs free energy, isodesmic reactions and orbital energies (HOMO-LUMO). These results are compared with the fluorinated cyclopropanes keto-enol system. Enthalpies, entropies and dipole moments are reported.
\end{abstract}

Key words: Cyclic Alkene; Tautomerism; Fluorinated Cyclic Alkene; DFT.

\section{Introduction}

Recently [1] we have studied cyclopropanone and cyclopropenol-(1) (Scheme 1) and have shown that cyclopropanone is by $17.684 \mathrm{kcal} / \mathrm{mol}$ more stable than cyclopropenol-(1). This was confirmed by a positive Gibbs free energy, $\Delta G(\Delta G=17.509 \mathrm{kcal} / \mathrm{mol})$, which indicates that the keto-enol tautomerism is nonspontaneous, and cyclopropanone is more stable than cyclopropenol-(1).

Also, it was found [1] that an increase in the number of substituting fluorine atoms causes a destabilization of cyclopropanone.

In this paper we study the effect of the methylene group on the three-membered ring and also of the stepwise fluorination of this methylenecyclopropanes/ 1-methylcyclopropene system in order to compare this effect with the previous work on the keto-enol system [1].

Much work has been done on the rearrangement of methylenecyclopropane [2-4], ring opening isomerization [5], decomposition [6], reactive intermediates [7] and single electron oxidation of methylenecyclopropene [8]. But no work was found on the stepwise fluorination of methylenecyclopropane.

DFT/B3LYP (G 03, Revision B.03) [9] is applied to examine first the methylenecyclopropane/ 1-methylcyclopropene system (Scheme 2) and then the

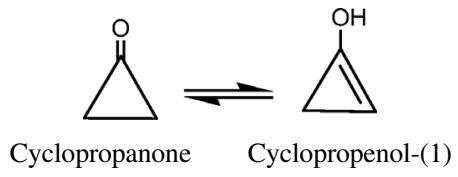

Scheme 1.

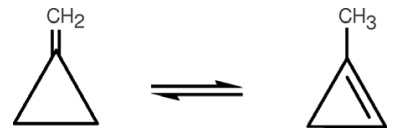

Methylenecyclopropane (1) 1-Methylcyclopropene (2)

Scheme 2.

stepwise fluorinated methylenecyclopropane/1-methylcyclopropene system. All calculations are done in the gas phase at $298.15 \mathrm{~K}$.

\section{Results and Discussion}

Density functional theory (DFT) calculations [9] are used to calculate fully the optimized geometries of fluorinated methylenecyclopropanes and 1-methylcyclopropenes. The molecular structure of the fluorinated methylenecyclopropane (1)/1-methylcyclopropene (2) system and Mulliken atomic charges are given in Figure 1. The calculated entropies, enthalpies and dipole moments of 11 compounds are listed in Table 1 . The calculated Gibbs free energies, isodesmic reactions and orbital energies are given in Tables 2, 3 and 4. 


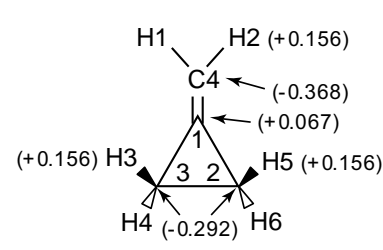

1

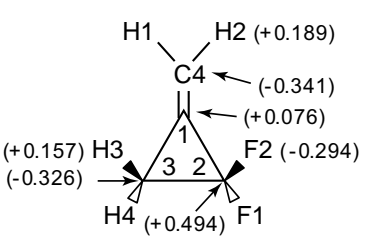

5

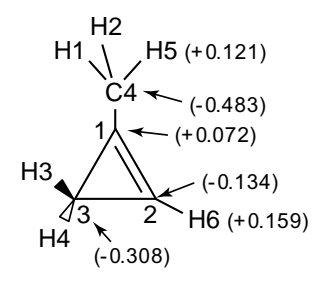

2

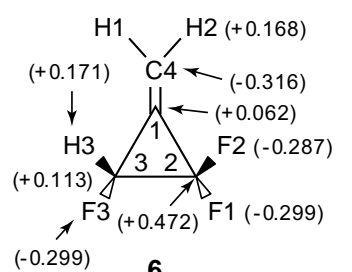

6

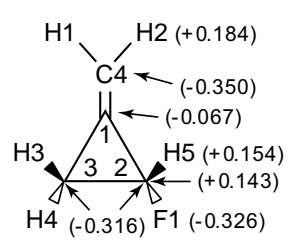

3

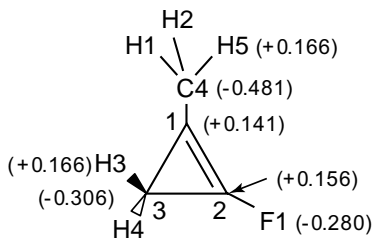

7

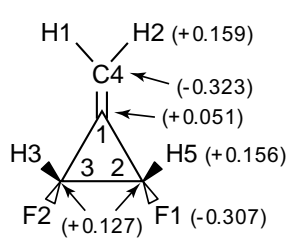

4

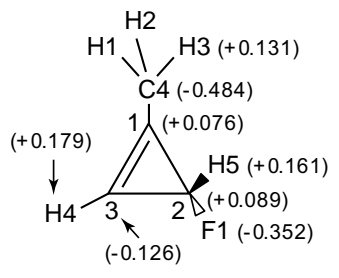

8

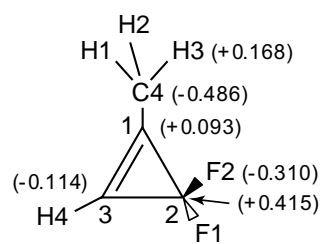

9

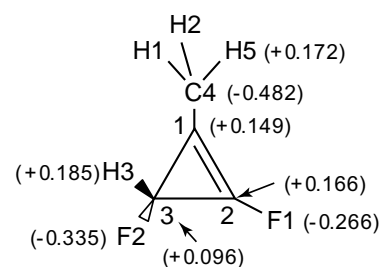

10

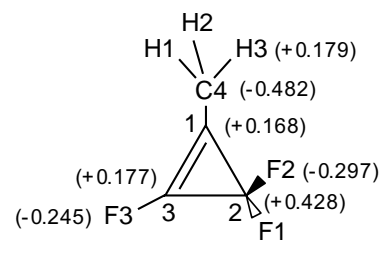

11

Fig. 1. Molecular structure of fluorinated methylenecyclopropanes and 1-methylcyclopropenes with Mulliken atomic charges in parenthesis.

Table 1. Calculated entropy $S$, enthalpy $H$ and dipole moment $\mu$ of fluorinated methylenecyclopropanes and 1-methylcyclopropenes (see Fig. 1 for numbering).

\begin{tabular}{lccc}
\hline Compound & $S\left(\mathrm{cal} \mathrm{mol}^{-1} \mathrm{~K}^{-1}\right)$ & $H$ (Hartrees) & $\mu(\mathrm{D})$ \\
\hline $\mathbf{1}$ & 66.077 & -153.960025 & 0.382 \\
$\mathbf{2}$ & 65.809 & -153.941643 & 0.916 \\
$\mathbf{3}$ & 71.595 & -251.736708 & 2.078 \\
$\mathbf{4}$ & 77.298 & -349.511797 & 3.429 \\
$\mathbf{5}$ & 76.400 & -349.529591 & 2.910 \\
$\mathbf{6}$ & 82.745 & -447.304853 & 3.316 \\
$\mathbf{7}$ & 71.136 & -251.732551 & 2.136 \\
$\mathbf{8}$ & 70.942 & -251.726023 & 2.926 \\
$\mathbf{9}$ & 75.496 & -349.523916 & 3.928 \\
$\mathbf{1 0}$ & 76.130 & -349.519106 & 3.101 \\
$\mathbf{1 1}$ & 80.829 & -447.318392 & 3.632 \\
\hline
\end{tabular}

1 Hartree $=627.5095 \mathrm{kcal} / \mathrm{mol}$.

\subsection{Parent Compounds}

DFT calculations have shown that the difference in energy between compound $\mathbf{2}$ and compound $\mathbf{1}$ is 0.018382 Hartrees $(11.535 \mathrm{kcal} / \mathrm{mol})$, Table 1 , suggesting that $\mathbf{1}$ is more stable than 2 by $11.535 \mathrm{kcal}$ /mol.
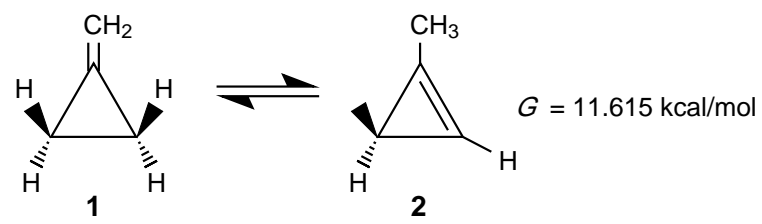

Scheme 3 .

This is confirmed by thermodynamic calculations (Table 2) which show a positive Gibbs free energy $(\Delta G=11.615 \mathrm{kcal} / \mathrm{mol})$ indicating a nonspontaneous reaction and that methylenecyclopropane (1) is more stable (Scheme 3). Comparing this energy with that of the keto-enol system $(\Delta G=17.509 \mathrm{kcal} / \mathrm{mol})$ [1] suggests that the carbonyl group stabilizes the threemembered ring more than the methylene group. It was found that in all alkene isomerizations [10], the forward reaction is favoured far more than in their ketoneto-enol counterparts, which agrees with the present work. This $\Delta G$ value $(11.615 \mathrm{kcal} / \mathrm{mol})$ will be taken as reference for determining the relative stability of fluorinated methylenecyclopropanes and 1-methylcyclopropenes. 
Table 2. Gibbs free energy $(\Delta G)$ of fluorinated methylenecyclopropanes and 1-methylcyclopropenes.

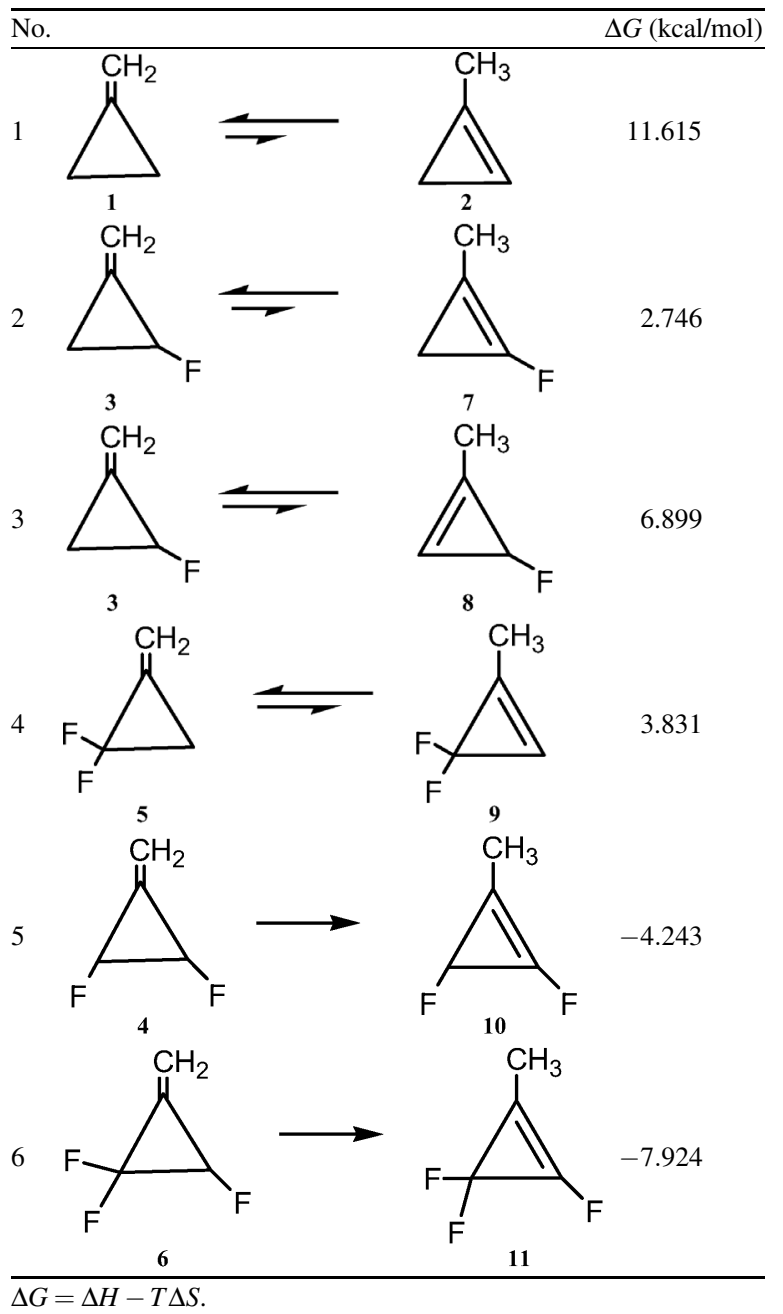

\subsection{Relative Stability of the Fluorinated \\ Methylenecyclopropane $\rightleftharpoons 1$-Methylcyclopropene System}

Introduction of fluorine causes a change in the atomic charges of the methylenecyclopropane $\rightleftharpoons$ 1-methylcyclopropene system, mainly where the fluorine atom is attached (Fig. 1).

\section{Effect of One F Atom}

Fluoromethylenecyclopropane (3) (Fig. 1) is an unsymmetrical compound and has two possibilities of forming 7 and 8 (Scheme 4).

Compound 7 is formed from a $\mathrm{H} 5$ shift from $\mathrm{C} 2$ (compound $\mathbf{3}$ ), while compound $\mathbf{8}$ is formed by a H3 shift from C3.

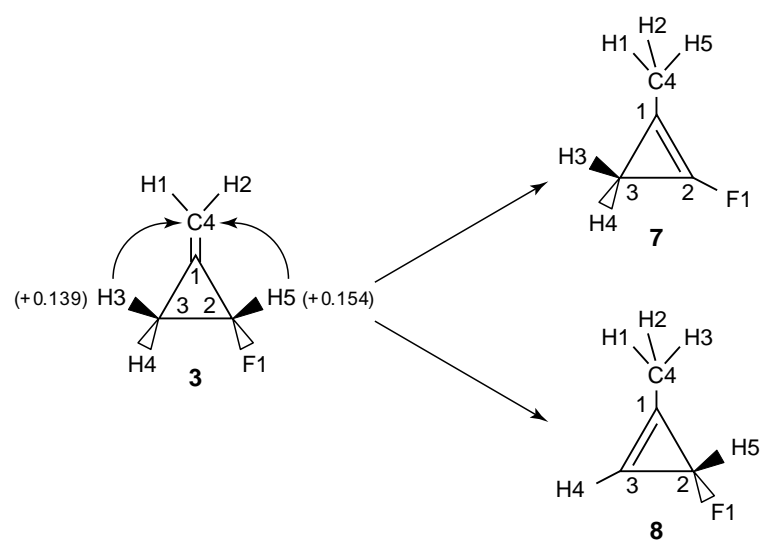

Scheme 4.

The $\mathrm{H} 5$ in compound 3 is more acidic $(+0.154)$ than $\mathrm{H} 3$ (+0.139). So compound 7 formed from the H5 shift may be favourable. This is indicated by No. 2 in Table 2 , where $\Delta G=2.746 \mathrm{kcal} / \mathrm{mol}$ is smaller than that of compound $8(\Delta G=6.899 \mathrm{kcal} / \mathrm{mol}$, No. 3 in Table 2). This suggests that the transformation from 3 to $\mathbf{7}$ is more likely to occur than from $\mathbf{3}$ to $\mathbf{8}$, i. e. compound $\mathbf{7}$ is more stable than $\mathbf{8}$. The stabilization effect is also supported by using the isodesmic reactions [11-18]. A negative value for the reaction indicates a less stable, and a positive value a more stable product. It can be seen that $\Delta H_{\mathrm{rxn}}=2.435 \mathrm{kcal} / \mathrm{mol}$ of compound 7 (No. 2 in Table 3) is more positive than that of compound $8\left(\Delta H_{\mathrm{rxn}}=-0.368 \mathrm{kcal} / \mathrm{mol}\right.$, No. 3 in Table 3), suggesting that $\mathbf{7}$ is stable relative to 8 .

\section{Effect of Two F Atoms}

There are two possibilities, case a and case b:

a. 2,3-Difluoromethylenecyclopropane (4) is a symmetrical compound (Fig. 1). The possible compound formed is compound 10, resulting from a H5 shift on $\mathrm{C} 2$ or from a $\mathrm{H} 3$ shift on $\mathrm{C} 3$ (Scheme 5).

The $\Delta G$ value is calculated to be $-4.243 \mathrm{kcal} / \mathrm{mol}$ (No. 5 in Table 2), which is less than the one for the parent compound (No. 1 in Table 2) indicating an increase in the stability of compound $\mathbf{1 0}$.

This is also supported by the isodesmic reaction, where $\Delta H_{\mathrm{rxn}}=2.433 \mathrm{kcal} / \mathrm{mol}$ of $\mathbf{1 0}$ (No. 7 in Table 3) is more positive than that of $\mathbf{4}\left(\Delta H_{\mathrm{rxn}}=0.794 \mathrm{kcal} / \mathrm{mol}\right.$, No. 6 in Table 3), indicating that $\mathbf{1 0}$ is relatively more stable than 4 , i. e. the two fluorine atoms destabilize the methylenecyclopropane.

b. 2,2-Difluoromethylenecyclopropane (5) (Fig. 1) is unsymmetrical. The compound that might be formed is 9 resulting from a $\mathrm{H} 3$ shift on $\mathrm{C} 3$ (Scheme 6). 
Table 3. Evaluation of substituent effects on methylenecyclopropanes and 1-methylcyclopropenes via isodesmic reactions.

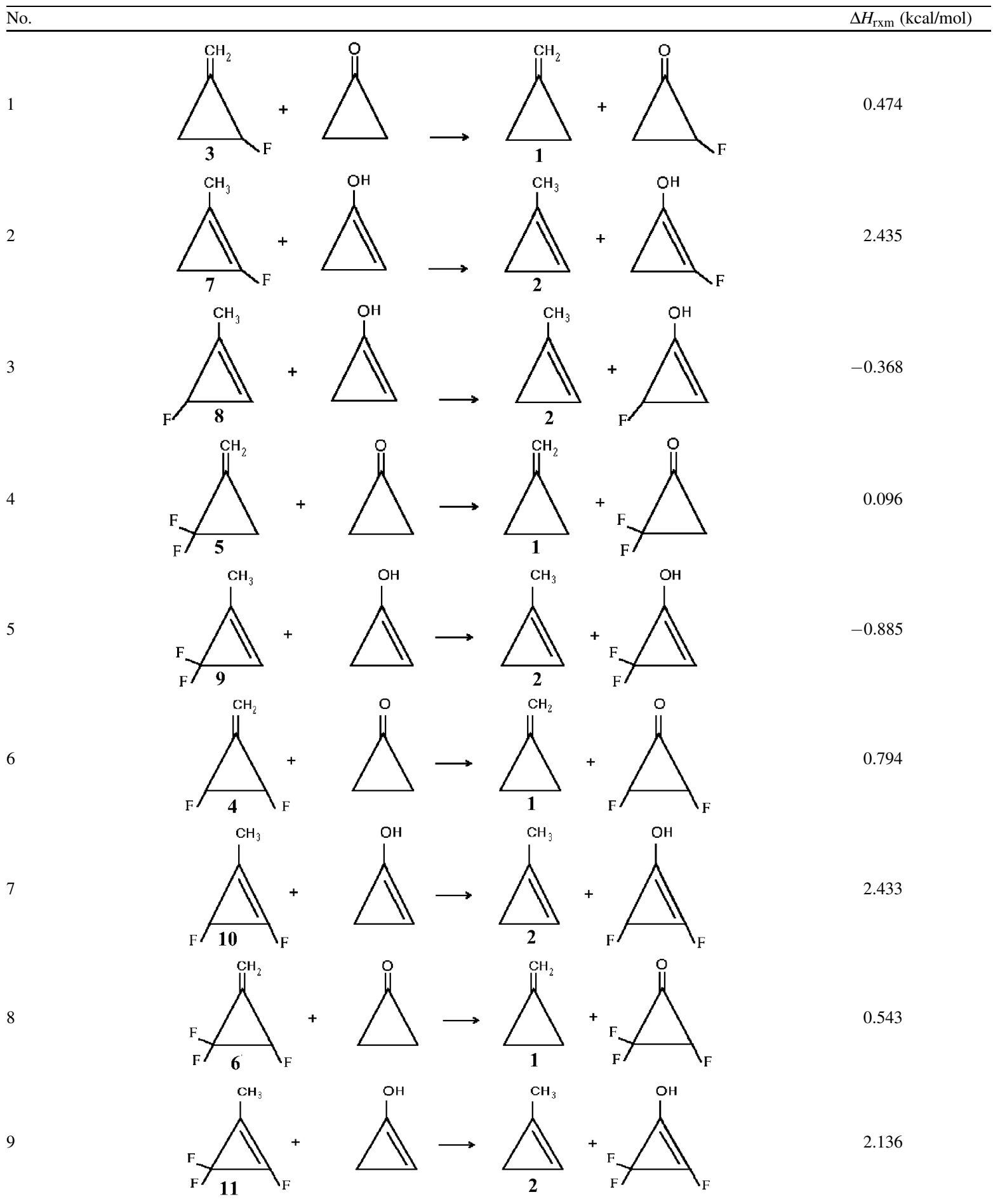

$\Delta H_{\text {rxn }}=\Sigma \Delta H_{\text {product }}-\Sigma \Delta H_{\text {reactant }}$. 

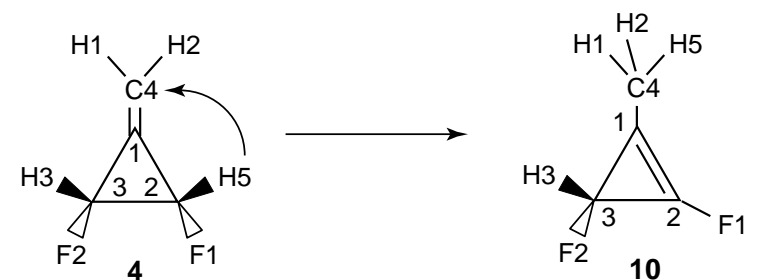

Scheme 5 .
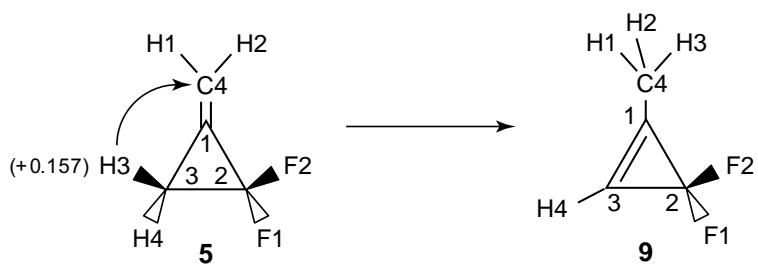

Scheme 6 .

The $\Delta G$ value of 5 is calculated to be $3.831 \mathrm{kcal} / \mathrm{mol}$ (No. 4 in Table 2), which is less than that of the parent compound $(\Delta G=11.615 \mathrm{kcal} / \mathrm{mol})$. This suggests that the two fluorine atoms destabilize the methylenecyclopropane (1), i. e. increase the stability of 1-methylcyclopropene (2), but still 5 is more stable than 9 because of its positive $\Delta G$ value $3.831 \mathrm{kcal} / \mathrm{mol}$.

This is also supported by the isodesmic reaction, where $\Delta H_{\text {rxn }}=0.096 \mathrm{kcal} / \mathrm{mol}$ of compound 5 (No. 4 in Table 3$)$ is more positive than that of $9\left(\Delta H_{\mathrm{rxn}}=\right.$ $-0.885 \mathrm{kcal} / \mathrm{mol}$, No. 5 in Table 3 ) indicating that 5 is relatively more stable than 9 .

It can be seen from Table 2, that the $\Delta G$ value of compound 4 to compound $\mathbf{1 0}$ (No. 5 in Table 2) is smaller than that of compound 5 to compound 9 (No. 4 in Table 2), suggesting the greater effect of the two fluorine atoms in the case of a (two F atoms not on the same $\mathrm{C}$ atom) compared to that of case $\mathrm{b}$ (two $\mathrm{F}$ atoms on the same $\mathrm{C}$ atom).

\section{Effect of Three F Atoms}

2,2,3-Trifluoromethylenecyclopropane (6) (Fig. 1) has one possibility of compound formation. The compound formed is compound $\mathbf{1 1}$ resulting from a $\mathrm{H} 3$ shift on $\mathrm{C} 3$. The positive charge of $\mathrm{H} 3$ in compound 6 is +0.171 (Scheme 7), which is more acidic than the parent methylenecyclopropane proton $(+0.156, \mathbf{1}$, Fig. 1).

So the product formation may be favoured by a relatively higher stability compared to the parent compound. This is indicated by No. 6 in Table 2, where $\Delta G=-7.924 \mathrm{kcal} / \mathrm{mol}$ is less than the one of the

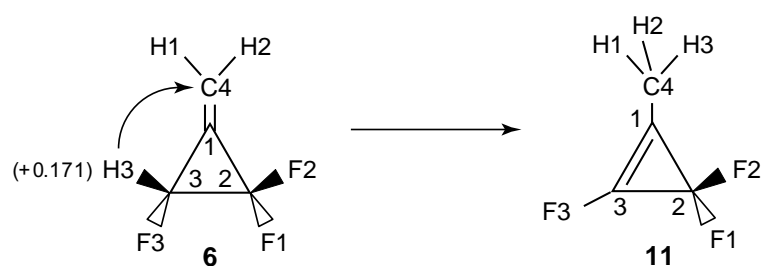

Scheme 7.
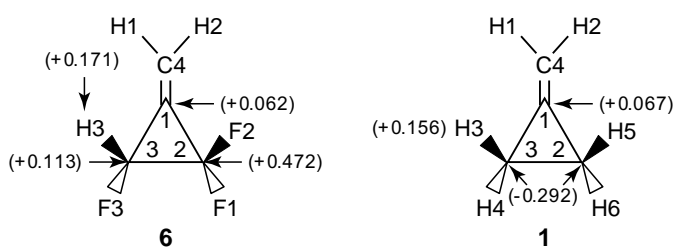

Scheme 8 .

parent compound $(\Delta G=11.615 \mathrm{kcal} / \mathrm{mol})$. This result is also supported by isodesmic reactions, where $\Delta H_{\mathrm{rxn}}=2.136 \mathrm{kcal} / \mathrm{mol}$ of $\mathbf{1 1}$ (No. 9 in Table 3) is more positive than that of $\mathbf{6}\left(\Delta H_{\mathrm{rxn}}=0.543 \mathrm{kcal} / \mathrm{mol}\right.$, No. 8 in Table 3 ). This suggests a relative stability of compound 11. Thus $\mathbf{1 1}$ is favoured over 6, which agrees with the previous work on the keto-enol system $[1,19]$ where the enol form is favoured over the ketone form.

The calculated Mulliken charge distribution in compound 6 (Fig. 1) may give a plausible explanation for its destabilization. The calculated charges at carbon atoms 2 and 3 are more positive in 6 than in 1 (Scheme 8). The positive charge adjacent to methylene group is destabilizing due to the electrostatic repulsion between the two carbon atoms $\mathrm{C} 2$ and $\mathrm{C} 3$, and $\mathrm{C} 1$. Therefore this repulsion might be responsible for the destabilization of $\mathbf{6}$. The hydrogen atom $\mathrm{H} 3$ becomes more acidic $(+0.171)$ in compound $\mathbf{6}$ than in compound $\mathbf{1}(+0.156)$. Increasing the acidity of hydrogen atom $\mathrm{H} 3$ is likely to be important for the easy formation of compound 11 (Scheme 7). Thus compound $\mathbf{1 1}$ is favoured over compound $\mathbf{6}$ in a similar explanation to that given in previous works on $2 \mathrm{H}$-perfluorocyclobutanone [20] and $2 \mathrm{H}$ perfluorocyclopentanone $[11,21,22]$.

\subsection{Dipole Moment of Fluorinated Methylenecyclopropane and 1-Methylcyclopropene}

Stepwise fluorination affects the dipole moment of all compounds, as shown in Table 1.

Introduction of a fluorine atom into methylenecyclopropane increases the dipole moment from 0.382 
Table 4. Calculated orbital energies (HOMO and LUMO, in $\mathrm{eV}$ ) of fluorinated methylenecyclopropanes and 1-methylcyclopropenes (see Fig. 1 for numbering).

\begin{tabular}{crrc}
\hline Compound & HOMO & LUMO & $E_{\mathrm{g}}=$ LUMO - HOMO \\
\hline $\mathbf{1}$ & -6.913 & 0.459 & 7.372 \\
$\mathbf{2}$ & -6.418 & 0.714 & 7.132 \\
$\mathbf{3}$ & -7.482 & -0.424 & 7.058 \\
$\mathbf{4}$ & -7.852 & -1.346 & 6.506 \\
$\mathbf{5}$ & -8.015 & -0.971 & 7.044 \\
$\mathbf{6}$ & -8.403 & -1.887 & 6.516 \\
$\mathbf{7}$ & -6.629 & 0.771 & 7.400 \\
$\mathbf{8}$ & -7.564 & 0.060 & 7.624 \\
$\mathbf{9}$ & -8.095 & -0.517 & 7.578 \\
$\mathbf{1 0}$ & -7.694 & -0.097 & 7.597 \\
$\mathbf{1 1}$ & -8.385 & -0.462 & 7.923 \\
\hline
\end{tabular}

Debye (1 without fluorination) to 2.078 Debye ( $\mathbf{3}$ with fluorination). This is due to the presence of the fluorine atom with a constructive resultant with a $-\mathrm{CH}_{2}$ group. It is shown from compound $\mathbf{4}$ that the two fluorine atoms increase the dipole moment to 3.429 Debye. This is because the resultant of the two fluorine atoms and the $-\mathrm{CH}_{2}$ group are in the same direction. In the case of the keto-enol system [1], introducing two fluorine atoms at the two carbon atoms decreases the dipole moment due to the presence of the two fluorine atoms in opposite direction with the carbonyl group. But when the two fluorine atoms are at the same carbon atom (compound $\mathbf{5}$, Fig. 1), the dipole moment is less than that of $\mathbf{4}$, because the resultant of the two fluorine atoms and the $-\mathrm{CH}_{2}$ group are not in the same direction. Compound $\mathbf{6}$ shows that the dipole moment is greater than that in compound $\mathbf{5}$, since the resultant of the fluorine atoms has a constructive direction with the $-\mathrm{CH}_{2}$ group. Similarly, the changes in the dipole moments of fluorinated 1-methylcyclopropenes can be explained (compounds $\mathbf{7 - 1 1}$ ).

\subsection{Orbital Energies (HOMO and LUMO) of Fluorinated Methylenecyclopropanes and 1-Methylcyclopropenes}

The introduction of fluorine atoms into methylenecyclopropane and 1-methylcyclopropene affects their

[1] A. El-Alali, A. A. Marashdeh, and S. M. Khalil, Z. Naturforsch. 58a, 749 (2003).

[2] W. R. Dolbier, Jr., C. R. Burkholder, A. L. Chaves, and A. Green, J. Fluorine Chem. 77, 31 (1996).

[3] A. Shancke, J. Fluorine Chem. 45, 129 (1989).

[4] A. Shancke, L. S. Schaad, and B. A. Hess, Jr., J. Mol. Struct. (Theochem.) 227, 311 (1991). orbital energies (HOMO and LUMO) compared with their parent compounds.

In the case of fluorinated methylenecyclopropanes (compounds 3-6, Table 4), an increase in the number of fluorine atoms causes a decrease in the energy gaps $\left(E_{\mathrm{g}}\right)$, but not steadily. It depends on the geometry of the compound. This suggests a decrease in the stability of compounds 3-6. In the case of fluorinated 1-methylcyclopropene compounds 7-11, Table 4, shows an increase in $E_{g}$ suggesting a stabilization of these compounds. This agrees with the present isodesmic reactions and thermodynamic calculations, where fluorination destabilizes compound $\mathbf{1}$ and stabilizes compound 2.

In the case of perfluorination of methylenecyclopropane (1) (Table 4), the energy gap decreases from $7.372 \mathrm{eV}$ (compound $\mathbf{1}$, without perfluorination) to $6.516 \mathrm{eV}$ (compound $\mathbf{6}$, with perfluorination), suggesting a destabilization of $\mathbf{1}$.

In the case of perfluorination of 1-methylcyclopropene (2), $E_{\mathrm{g}}$ increases from $7.132 \mathrm{eV}$ (compound 2 , without perfluorination) to $7.923 \mathrm{eV}$ (compound 11, with perfluorination), suggesting a stabilization of compound 11. This agrees with the present thermodynamic and isodesmic calculations. Thus perfluorinated 1-methylcyclopropene $\mathbf{1 1}$ is present in substantial concentration.

\section{Conclusion}

It can be concluded that methylenecyclopropane is more stable than 1-methylcyclopropene by $11.535 \mathrm{kcal} / \mathrm{mol}$. The methylene group less stabilizes the three-membered ring relative to the carbonyl group. The stability of methylenecyclopropane was found to decrease on fluorination, similar to that in the case of cyclopropanone. Perfluorinated 1-methylcyclopropene was found to be present in substantial concentration. These results were confirmed by Gibbs free energy calculations, isodesmic reactions and orbital energies.

[5] M. Itazaki, Y. Nishaihara, H. Takimoto, C. Yoda, and K. Osakada, J. Mol. Catalysis A 241, 65 (2005).

[6] P. Davison, H. M. Frey, and R. Walsh, Chem. Phys. Lett. 120, 227 (1985).

[7] W. E. Billups, A. J. Blakeney, N. A. Rao, and J. D. Buynak, Tetrahedron 37, 3215 (1989). 
[8] H. Ikeda, H. Namai, N. Kato, and T. Ikeda, Tetrahedron Lett. 47, 2857 (2006).

[9] M. J. Frisch, G. W. Trucks, H. B. Schlegel, G. E. Scuseria, M. A. Robb, J. R. Cheeseman, J. A. Montgomery, Jr., T. Vreven, K. N. Kudin, J.C. Burant, J.M. Millam, S. S. Iyengar, J. Tomasi, V. Barone, B. Mennucci, M. Cossi, G. Scalmani, N. Rega, G. A. Petersson, H. Nakatsuji, M. Hada, M. Ehara, K. Toyota, R. Fukuda, J. Hasegawa, M. Ishida, T. Nakajima, Y. Honda, O. Kitao, H. Nakai, M. Klene, X. Li, J.E. Knox, H.P. Hratchian, J. B. Cross, C. Adamo, J. Jaramillo, R. Gomperts, R. E. Stratmann, O. Yazyev, A. J. Austin, R. Cammi, C. Pomelli, J. W. Ochterski, P. Y. Ayala, K. Morokuma, G. A. Voth, P. Salvador, J. J. Dannenberg, V. G. Zakrzewski, S. Dapprich, A. D. Daniels, M. C. Strain, O. Farkas, D. K. Malick, A. D. Rabuck, K. Raghavachari, J. B. Foresman, J. V. Ortiz, Q. Cui, A. G. Baboul, S. Clifford, J. Cioslowski, B. B. Stefanov, G. Liu, A. Liashenko, P. Piskorz, I. Komaromi, R. L. Martin, D. J. Fox, T. Keith, M. A. AlLaham, C. Y. Peng, A. Nanayakkara, M. Challacombe, P. M. W. Gill, B. Johnson, W. Chen, M. W. Wong, C. Gonzalez, and J.A. Pople, Gaussian, Inc., Pittsburgh, PA 2003.
[10] P. E. Lindner and D. M. Lemal, J. Am. Chem. Soc. 119, 3267 (1997).

[11] M. S. Al-Noeemat, R. A. Al-Ma'ani, and S. M. Khalil, Z. Naturforsch. 58a, 738 (2003).

[12] W. H. Hehre, R. Ditchfield, L. Radom, and J. A. Pople, J. Am.. Chem. Soc. 92, 4796 (1970).

[13] M. H. Lien and A. C. Hopkinson, J. Phys. Chem. 88, 1513 (1984).

[14] S. M. Khalil and H. M. Jarjis, Z. Naturforsch. 46a, 247 (1990).

[15] H. M. Jarjis and S. M. Khalil, J. Chem. Soc. Perkin Trans. 2, 1701 (1986).

[16] W. F. Reynolds, P. Dais, R. W. Taft, and R. D. Topsom, Tetrahedron Lett. 22, 1795 (1981).

[17] W. F. Al-Halasah and S. M. Khalil, Z. Naturforsch. 59a, 980 (2004).

[18] B. M. Salim and S. M. Khalil, Z. Naturforsch. 60a, 47 (2005).

[19] P. E. Lindner and D. M. Lemal, J. Am. Chem. Soc. 119, 3259 (1997).

[20] M. I. Sway, I. D. Al-Shawabkeh, and S.M. Khalil, Z. Naturforsch. 59a, 838 (2004).

[21] P. E. Lindner and D. M. Lemal, J. Org. Chem. 61, 5109 (1996).

[22] Y. Kwon, J. Mol. Struct. (Theochem.) 488, 93 (1999). 